\title{
Challenges of Structure in Today's Architectural, Economic and Social Context
}

\author{
Jorge Bernabeu Larena ${ }^{1}$ and Alejandro Bernabeu Larena ${ }^{2}$ \\ 1. Faculty of Civil Engineering, Technical University of Madrid, Madrid 28004, Spain \\ 2. Faculty of Architecture, Technical University of Madrid, Madrid 28004, Spain
}

\begin{abstract}
The recent establishment of a digital culture and society, together with current financial crisis and urgent energetic and climatic needs, has radically changed the architectural scene from the optimism of some years ago to a situation of uncertainty and huge social demands and challenges. In this context, it is suggested to rethink the role of structure in architecture, such as an enabler, a guide and a catalyst. The purpose of this paper is to present the economic, cultural and social context in which architecture develops nowadays. The method, to suggest a discussion on which role the structure may adopt in the architecture to come. The achievement, to highlight its potential to face current requirements and challenges.
\end{abstract}

Key words: Structural engineering, design concept, social architecture, critics.

\section{Introduction}

The end of 20th century and the beginning of 21st has been characterized in architecture by a strong development of design, analysis and construction technologies. This technical development has generated an unprecedented situation of great freedom, in which almost every form can be solved and erected. Frank Gehry's Guggenheim museum in Bilbao or Herzog \& de Meuron's Beijing Stadium are paradigmatic examples of this architectural freedom [1].

In this context, being the structural requirements overcome, the purpose of structure and its relation to architecture had to be reconsidered. And indeed, while in earlier times, the development of architectural form was directly related to the emergence of new structural materials or systems, the new technical control and formal freedom required a further consideration on the relation between architecture and structure, and on the potential of structure as a design

Corresponding author: Jorge Bernabeu Larena, Dr., Eng., research fields: history of construction, public works heritage, cultural landscape and structural engineering. E-mail: jorge.bernabeu@upm.es. tool. New structural design strategies had to be developed, in order to consider structural behavior and requirements not as annoying constraints, but as design opportunities, within which develop architectural form and composition [2].

However, the amazing development of digital technologies and its strong establishment in society, together with the urgent energetic and financial needs, have radically changed the scene. From the optimistic, and maybe irresponsible, architectural freedom of the beginning of the twenty-first century, people have now moved into a situation of architectural uncertainty, in which the design parameters and priorities of just some years ago are no longer valid, and have to be revised, reordered or redefined.

And in this context, it is suggested once again to rethink the role of structure in architecture, both as an enabler, a guide or a catalyst. The final goal of this paper is to present the economic, cultural and social context in which architecture develops nowadays - The research procedure is based on a discussion about the role the structure may adopt in the architecture to come. What is new in this study is the critic comparative analysis between different 
contemporary projects digital culture, society and architecture.

The recent establishment of a digital culture is radically changing the social and cultural context in which architecture evolves, transforming its main parameters and factors [3]. Among them, it is interesting to highlight the following:

- Redefinition of the relation to the physical world. It entails the transformation of the concept of materiality, in benefit to virtual reality, from spatial recreation to cyber-sociality, and the relation or opposition between real and virtual (Fig. 1);

- Emphasis on individual preferences and choices, altogether with the establishment of a globalized culture and society. The widespread introduction of globalized products and systems that may be personally set and customized, reveals this duality between standard and unique, global and personal, collective and individual (Fig. 1);

- Relevance of events. What happens, the content, becomes more important than any physical thing-the container. As an example, the impressive establishment of the internet, with instant update of contents following the last events and news, takes the user into a vertiginous process that gives the feeling of living in a permanent present.

Related to architecture, these factors entail the crisis of traditional tectonic, and its relation and dependence to physical materiality, claiming for the establishment of a new tectonic, able to reconcile abstraction of virtual society and culture with the physical concretion that architecture requires [1].

Many projects have been presented in recent years that can be considered in a broad sense as digital architecture, showing architects' interest and concern on digital demands and motivations, and illustrating also the context of architectural freedom (Fig. 2).

Among them, Zaha Hadid, together with his partner Patrick Schumacher, has proposed an ambitious theoretical argument or manifesto. It is based in integrating in the development process of a project a number of factors and complexities, related not only to the project or to construction and architectural techniques, but to all kind of economic, social and cultural motivations and suggestions [4, 5]. This "parametricism” proposal, that has been presented as the new architectural style after modernism, proposes an understanding of architecture as the result of a set of different factors and parameters that, combined, differentiated and correlated among them, defines a malleable formal development. It identifies besides a number of principles from which project design development arises, and that are organized as negative or taboos (rigid forms, repetitions, etc.) and positive or dogmas (soft forms, differentiated and interdependent systems, etc.). It finally raises the question about structure, if it is just another parameter to be considered in the equation, or if it can actively
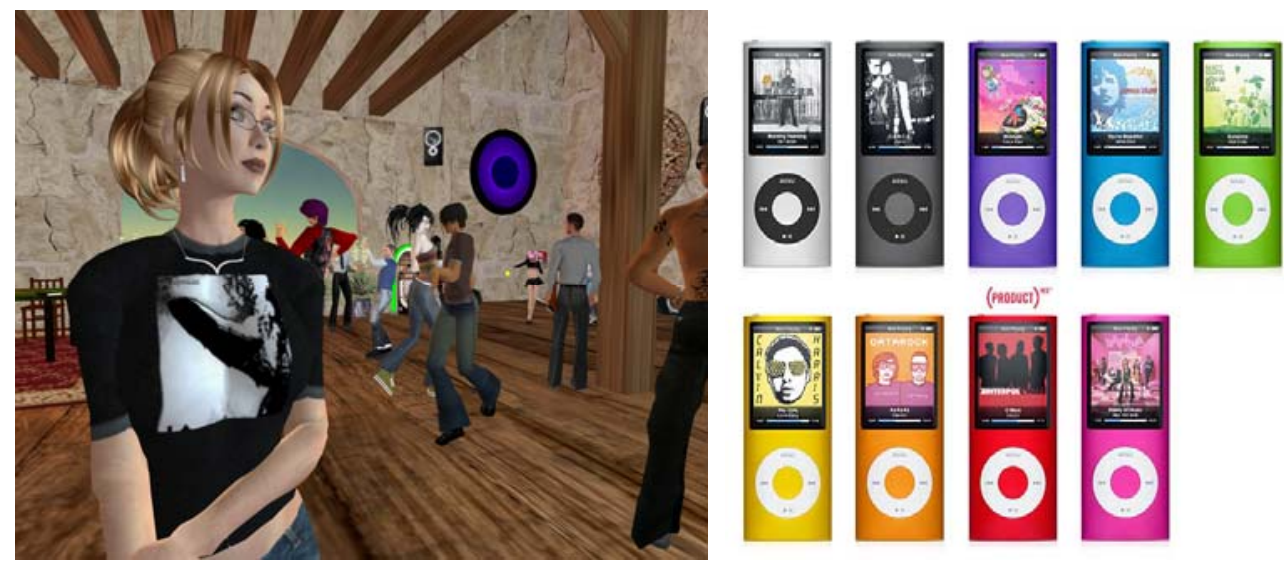

Fig. 1 Digital social and cultural context, virtual reality and cyber-sociability—secondlife, duality between standard/global and unique/personal-ipod. 


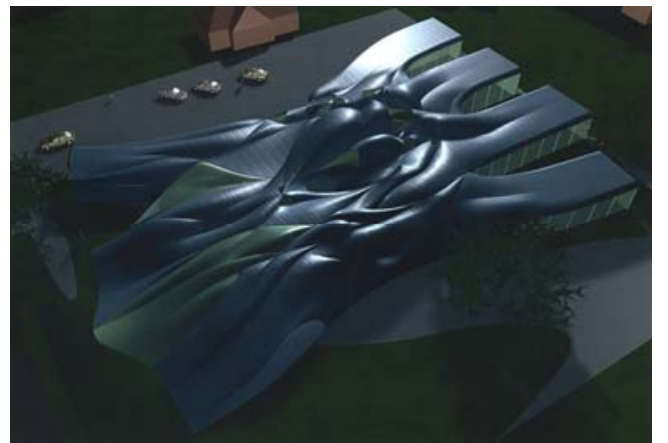

(a)

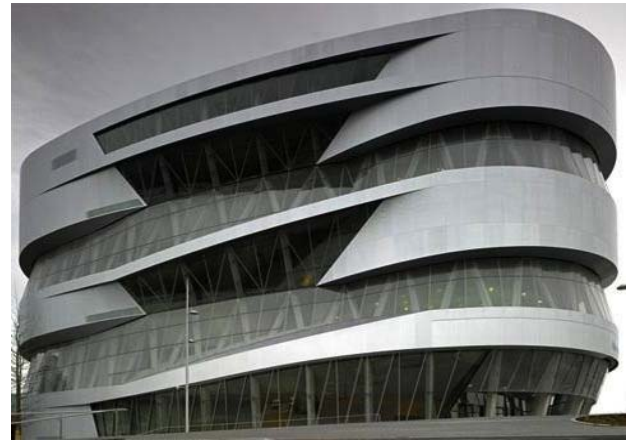

(b)

Fig. 2 (a) Digital architecture, Soft Office, Warwickshire (UK), 2002. NOX; (b) Mercedes Benz Museum, Stuttgart (Germany), 2006, UN Studio.

participate in the definition of the patterns that govern and control the parametric development of the project.

It is maybe too early to evaluate the result and the influence of these proposals in the architecture to come. However, they still lack, in its practical application, of the coherence and in depth analysis and development that would be expected from their theoretical considerations. Overly concerned by formal and visual aspects, in accordance to digital imagery of nowadays [6,7], they avoid to face in depth the complex challenges that digital architecture proposes, as link and catalyst between virtual society and the tectonic and material reality of built

\section{environment.}

Accordingly, the structure of these project lacks on its side of new approaches or strategies, and refuse to lead the process in depth, concentrating in adequately resolve the forms proposed by the architects. The complex geometries of Phaeno Science Centre, by Zaha Hadid and Graz Music Theater, by UN Studio, illustrate this situation. In both cases, the structure, developed by two of the most relevant and innovative engineers of nowadays (Hanif Kara and Cecil Balmond, respectively), has been brilliantly solved, is elegant, interesting and well adapted to architectural forms and geometries [8, 9]. But it does not represent
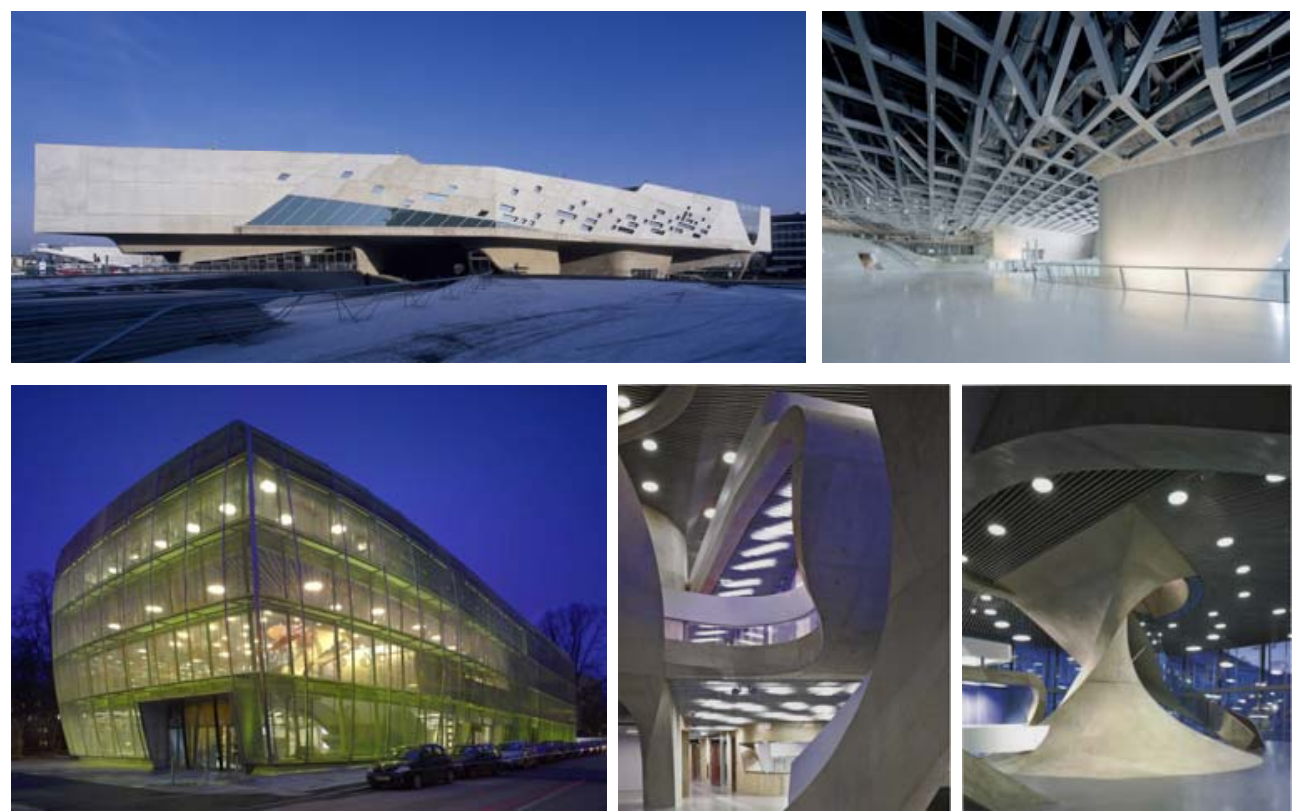

Fig. 3 Phaeno Science Center, Wolfsburg (Germany), 2005. Zaha Hadid Architects/Adams Kara Taylor, Graz Music Theater, Graz (Austria), 2008, UN Studio/Ove Arup \& Partners. 
neither in both cases any relevant novelty on structural systems or types, nor establish any link or approach to the big questions that digital architecture raises (Fig. 3).

\section{Energetic, Climatic and Economic Needs, The Architectural Response}

Current financial crisis, altogether with increasingly urgent energetic and climatic needs, questions the final purpose of contemporary architecture and construction, and strongly suggests decay of visual leadership in favor of functionality, resources optimization and cost control.

The concern for the environment and the need to preserve it, reducing the emission of pollutants, as well as decreasing energy and natural resources consumption, is present in society for several years now. There are therefore many architectural projects concerned by these issues, especially in reducing energy consumption, both for environmental reasons and for decreasing building operating costs. Their interest has focused in many cases in the façade, that is becoming more and more sophisticated. This sophistication of the façade responds both to the incorporation of advanced materials and climate control or energy uptake systems, and to visual and aesthetic motivations, related to technological and digital imagery (Fig. 4).

Likewise, environmental certifications have gone from being practically unknown in its beginnings in

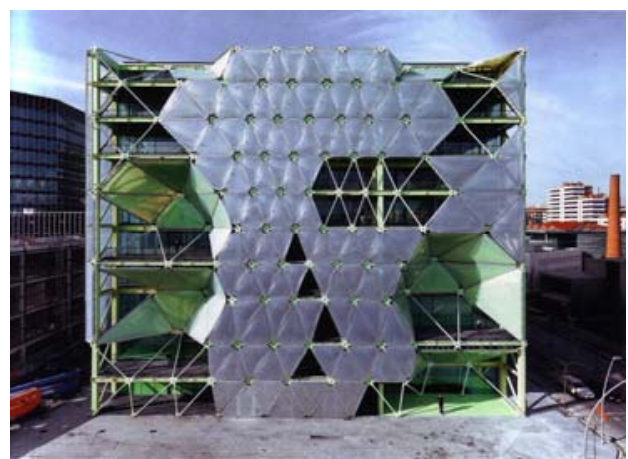

(a) architecture, twenty years ago, to be highly demanded nowadays, confirming the concern, or at least the interest, of society towards climatic and energetic sustainability. However, there are several issues that may be questioned when considering environmental certification [10]. First of all, it is important to consider to what extent it is possible to measure the sustainability of a building. Secondly, if environmental architecture consists just in complying with the different certification criteria, it risks to be excessively neutral and banal. And finally, the high demand of environmental certificates by big brands and organizations, denotes their concern not so far in the environmental needs, but in being considered environmentally responsible or friendly (Fig. 4). Considering so, certification is no longer a mean, but an end in itself, loosing much of its true potential.

In addition, or as an alternative, to these approaches, the following two proposals, completely different one from each other, illustrate and raise several issues that are key for considering sustainable architecture:

First, Glenn Murcutt projects, widely acknowledged since the Pritzker prize in 2002, illustrate a straightforward, subtle and responsible approach to sustainable architecture, not based on incorporating complex energy control systems, but in working in harmony with nature $[11,12]$. And indeed, what Murcutt architecture proposes is a sensitive approach to nature and to natural rhythms, the respect to landscape scale, the prevention of natural resources,

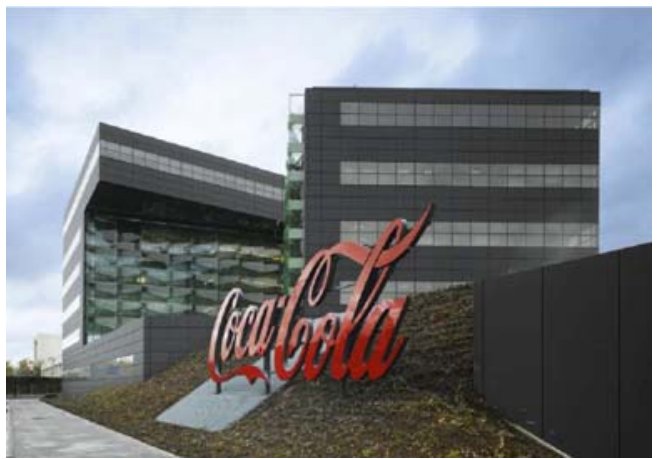

(b)

Fig. 4 (a) Media-TIC offices building. Barcelona (Spain), 2010, Cloud 9; (b) Coca-Cola Headquarters, Madrid (Spain), 2009, De Lapuerta and Asensio, The building has achieved a gold LEED certificate. 
and above all, the awareness of the responsibility of architecture in the transformation of the world that entails any construction $[13,14]$.

Secondly, Foster's project for Masdar city in Abu Dhabi, a sustainable, zero-carbon, zero-waste and car free city, exemplifies the model of "smart cities" projects that are proliferating nowadays, from Europe or the United States to Latin America or Asia [15]. Besides the technological and somehow futuristic approach of the project, what is interesting to highlight here is the idea of facing environmental needs in a bigger scale than building construction, aware of the fact that the garden city and urban sprawl models prevent any sustainable program, and that new city developments have therefore to be adopted $[16,17]$. Accordingly, Masdar city proposes a high urban density model, with controlled buildings height, by reducing street width and incorporating an efficient underground public transport network (Fig. 5). As a result of this model, the need to move in private transport decreases, and therefore energy consumption and pollution is reduced.

Moreover, worldwide financial crisis has radically changed the optimistic and even unconcerned panorama of just some years ago, passing to a situation of economic restraint, and placing architects in the spotlight [18]. Terms and conditions in which projects are developed have indeed significantly changed, affecting the way architects work, while the role and responsibility of architecture towards society

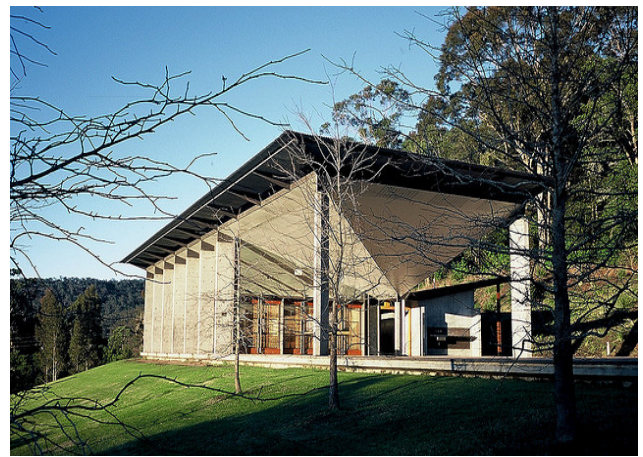

(a) is more evident than ever.

To this demanding situation, architecture has not been able yet to decisively respond. It is aware that the situation has changed, and that it can no longer consider the same project parameters and principles that some years ago, that living and working conditions have to evolve. But it has not been able yet to clearly formulate the new criteria that would guide design process. It is probably premature therefore to evaluate and to draw conclusions on how might architecture responds concretely to the current financial crisis.

However, if people attend to projects carried out on developing countries or degraded neighborhoods, that share some of the needs arising from current crisis situation, especially in terms of economic restraint and efficient use of resources, them might extract some findings that help to frame the situation.

In this sense, projects by Diébédo Francis Keré in Burkina Faso and Alejandro Aravena in Chile are especially significant.

First, Francis Keré projects have gained international recognition for its successful combination of modern construction techniques and local traditional wisdom and materials, for the minimum resources employed, and for the architect's complete implication in the project [19].

Indeed, for Gando's primary school project, built in 2004 and subsequently extended in 2008, Francis Keré conceived the project, raised the necessary funds

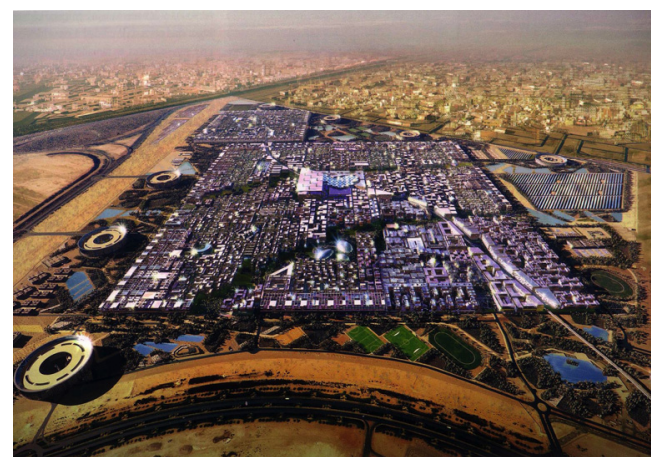

(b)

Fig. 5 (a) Arthur \& Yvonne Boyd Art Center, Riversdale (Australia), 1998, Glenn Murcutt; (b) Masdar City, Abu Dhabi (United Arab Emirates), 2007, Foster \& Partners. 
to be carried out, designed it, organized the construction involving his neighbors and future users of the school, that worked as bricklayers and construction laborers, and supervised the works (Fig. 6). The result is a compromised, responsible and sustainable architecture, that satisfy people needs, that efficiently mitigates the stifling climate of the area, and that is configured and realized respectfully of local traditions and open to modern techniques.

For his part, Alejandro Aravena's work with Elemental focuses in the design of innovative models for public housing in Chile [20, 21]. The goal is to respond to two main concerns: the awareness of housing as an urgent social issue, and the promotion of a sustainable development of the city. To respond simultaneously to these two issues. Elemental's proposal is directly related to the idea of returning to the dense city, that has proved to be more sustainable, in terms of transportation, energy consumption and pollution generation, as has been discussed before, and that will bring inhabitants of shantytowns back towards the city center, favoring their integration and participation in the city life. Besides, the economic restraint of these projects made that there was no budget enough for building reasonable houses, in terms of quality of construction and surface.

Their inventive and social response consisted then in developing an open housing typology, actually built with the essentials for a minimum unit, and the void of a vacant space that can be filled afterwards by the inhabitants. The first realized project with this typology was built in Iquique in 2004, where the layout took the form of a collective row housing with an upper crenellated silhouette. The idea was then that the residents would build in the remaining void of the upper level, as their means allow. And actually, just one year after delivery most of the voids were filled in, completing the project (Fig. 7).

Several issues are important to highlight from these projects, that although not directly extrapolable to the general architectural financial crisis situation, raise some key elements for reflection and discussion, and
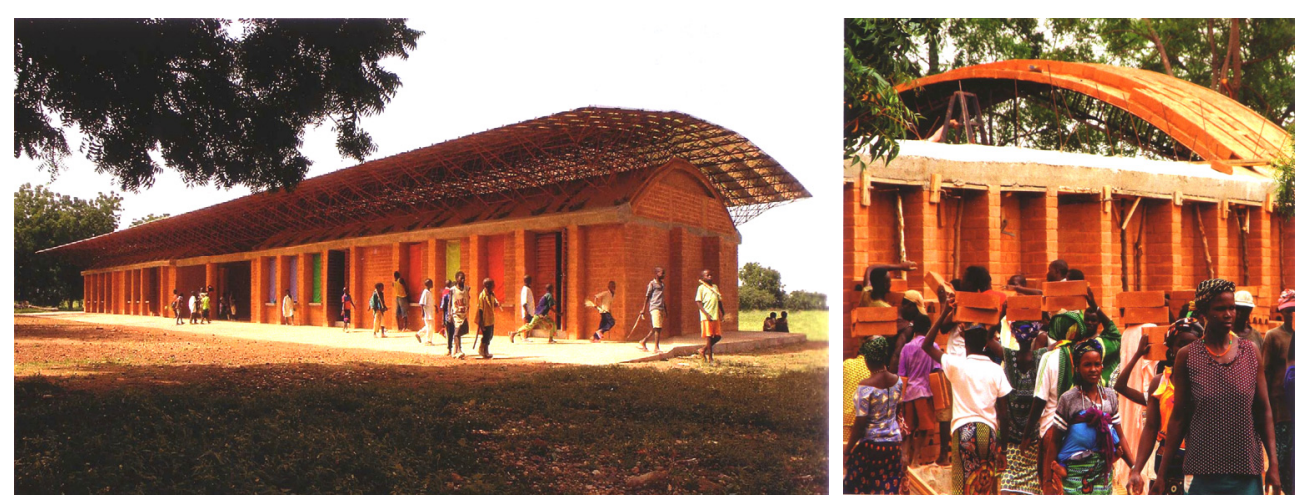

Fig. 6 Primary school extension, Gando (Burkina Faso), 2008, Diébédo Francis Keré.
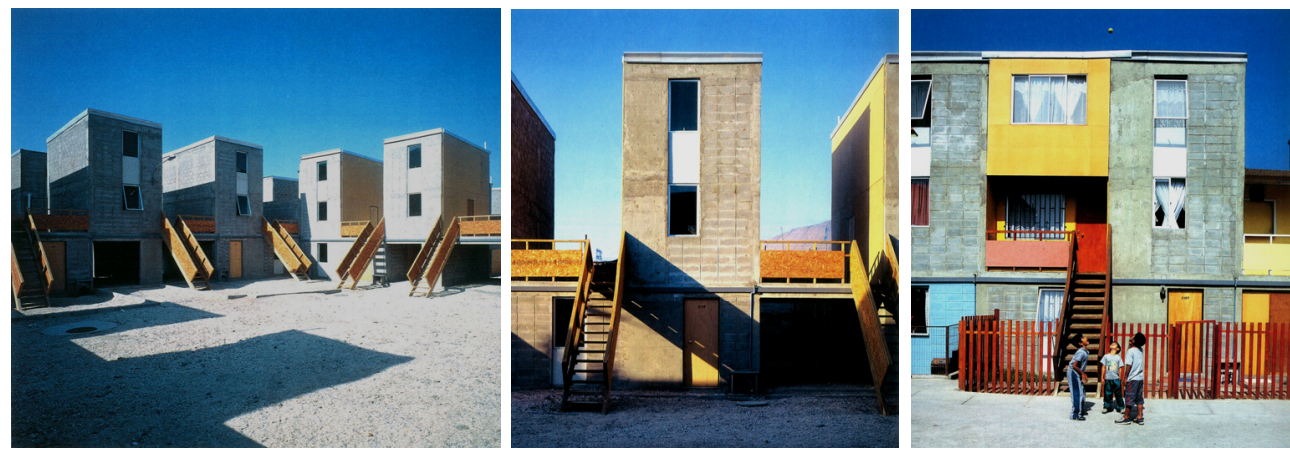

Fig. 7 Resorption of a shantytown for 100 families, Iguique (Chile), 2004, Elemental, Alejandro Aravena. 
suggest possibilities for current development.

First of all, it is crucial in both projects the intense participation and involvement of future users and inhabitants in the project development and during the construction process. The inhabitant is not just the final user of the project, but has an active role in its realization.

Secondly, the concept of beauty is not considered per se, but related to functionality and to the response to the needs. Beauty is in any case a consequence of the project, not a reason or a motivation factor of it.

Finally, application of sustainability criteria, use and optimization of local resources, and economic restraint, are not motivated in these projects by ideological reasons or to defend an idea, but just for practical matters, because it is the most logical and the only thing that can be done. It is not so much an option, but the natural solution to a necessity.

\section{The Challenges of Structure}

The irreversible establishment of a digital culture and society faces architecture and engineering to an unprecedented challenge that entails the redefinition of their basis: the concepts of tectonic and materiality. The goal is to relate them to digital and virtual parameters, changing somehow their present principles and characteristics.

Besides, current situation faces architecture and engineering to important ecological and economic challenges, to which they have to respond with responsibility and sensibility, conscious of its main social goal of satisfying people need's. This ethic of construction entails, among others, optimization of local resources, reduction of energy consumption, and consideration both of modern and traditional building techniques, in order to satisfy functional requirements with a minimum construction and maintenance cost. They finally suggest to rethink the concepts of beauty and aesthetics in architecture, and its dependence to purely visual aspects.

Architecture has understood the magnitude of these challenges, although it has not found yet the way to definitely face them. In turn, structure has not taken these challenges as their own, but adopted a secondary role. Structure is responding to architectural demands, in some cases accurately and with brilliant results, but without taking the initiative. And nevertheless, some of the suggestions are closely related to structure and engineering concepts and classical principles: to the way they relate to nature and integrate into the landscape, to the consideration of beauty in relation to functionality, or to the idea of optimization and minimization of the structure.

And if the authors consider simultaneously the projects of the Phaeno Science Center and the Primary School in Gando (Fig. 8), it arises that there is much work to be done to reconcile digital and virtual aspirations with sustainable and ecological demands, and that the answer to both concerns may be found by looking at the matter as a whole, that the potentiality and powerful possibilities of the first may be a key element to accurately respond to the second.
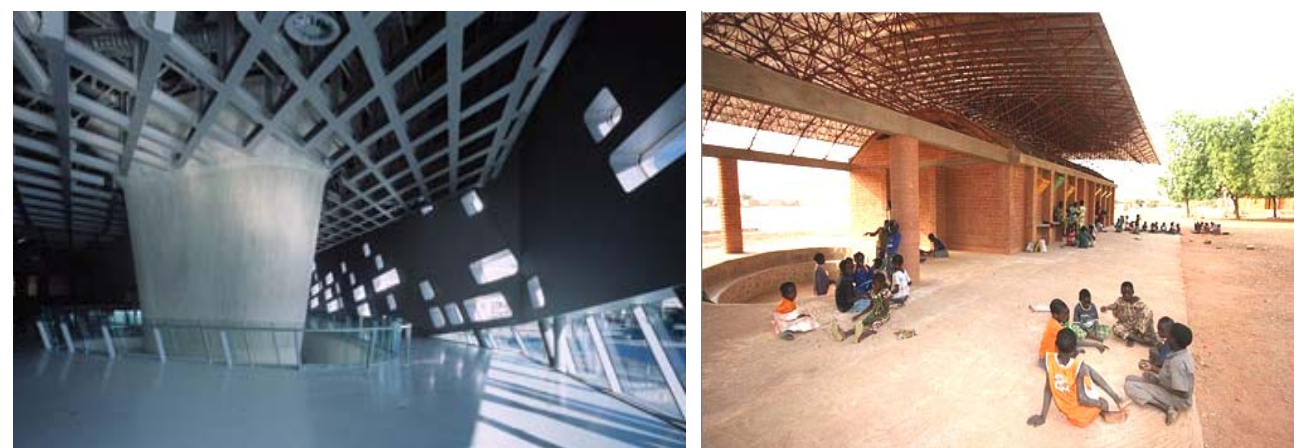

Fig. 8 Phaeno Science Center. Wolfsburg (Germany), 2005, Zaha Hadid/Adams Kara Taylor, Primary school extension, Gando (Burkina Faso), 2008, Diébèdo Francis Kéré. 


\section{Conclusions}

From these considerations, far from trying to establish a global conclusion, the authors propose an open discussion on the role of structure in contemporary architecture and its potential in helping it to successfully face current economic, social and cultural requirements:

Is structure able to establish a new tectonic, relating physical reality of construction to virtual culture?

Should structure step back, in benefit of services and climate systems, conscious of current energetic urgent needs?

Should structure act as an enabler to architectural freedom, or as a guide - or even a restrainer-to it? What role may structure play in the redefinition of beauty and aesthetics in architecture, faced to current situation?

And finally, is structure able to act as a catalyst, helping to reconcile digital culture suggestions with economic, social and environmental current requirements?

The challenge that current situation proposes both to architecture and structure is huge. It is about redefining the way people inhabit, how they occupy the world and use natural resources, and how they relate to each other and to nature. Let us face it with decision, coherence and responsibility.

\section{References}

[1] D. Azagra, A. Bernabeu, Free shape structures, Informes de la Construcción (Construction Reports) 64 (526) (2012) 133-142. (in Spanish)

[2] A. Bernabeu, What we talk about when we talk about structures, the function of structure in architecture, in: P. Cassinello, S. Huerta, J.M. de Prada Poole, R. Sánchez Lampreave (Eds.), Geometry and Proportion in Structural Design, Essays in Ricardo Aroca's Honour, Lampreave, 2010. (in Spanish)

[3] A. Picon, Digital Culture in Architecture, Birckhäuser, Basel, 2010.

[4] P. Schumacher, Parametricism as style-Parametricist manifesto, in: The 11th Architecture Biennale, Venice, 2008.

[5] P. Schumacher, Let the style war begin, Architect's Journal 16 (2010) 41-45.

[6] J. Steele, Architecture and Digital Revolution, Gustavo Gili editions, Barcelona, 2001. (in Spanish)

[7] J. Krauel, Digital Architecture, Innovation and Design, Links, Barcelona, 2010. (in Spanish)

[8] H. Kara, Design Engineering AKT Adams Kara Taylor, Actar, Barcelona, 2008.

[9] UN Studio in Motion, UN Studio, Phoenix Publishing and Media Group, Tianjin Ifengspace Culture \& Media Co., 2012.

[10] E. Prieto, To think, to count, to measure, key aspects in environmental certification, Arquitectura Viva (Live Architecture) 130 (2010) 112. (in Spanish)

[11] P. Drew, Leaves of Iron, Glenn Murcutt: Pioneer of an Australian Architectural Form, The Law Book Company, Sydney, 1985.

[12] E. Croquis, Glenn Murcutt, 1980-2012, Plumas de Metal $=$ Feathers of Metal, El Croquis, 2012, pp. 163-164.

[13] L. Moix, G. Murcutt, Architecture: More for less, in: L. Fernández-Galiano (Ed.), Fundación Arquitectura y Sociedad (Architecture and Society Foundation)/ Arquitectura Viva (Live Architecture), Madrid, 2010, pp. 132-139. (in Spanish)

[14] F. Fromonot, The success of an anti-star, Glen Murcutt, Pritzker Prize, Arquitectura Viva (Live Architecture) 83 (2002) 73-75. (in Spanish)

[15] S. Behling, Masdar, city of the future, Arquitectura Viva (Live Architecture) 130 (2010) 28-31. (in Spanish)

[16] L. Fernández-Galiano, The gulf and us, Dubai versus Masdar: Lessons from the crisis, Arquitectura Viva 130 (2010) 66-67. (in Spanish)

[17] L. Fernández-Galiano, Architecture and life, art in mutation, in: The Conference at the Royal Academy of Fine Arts of San Fernando, Madrid, 2012. (in Spanish)

[18] J.L. Mateo, After Crisis, Lars Müller Publishers, Baden, Switzerland, 2011.

[19] L. Moix, D.F. Kéré, Architecture: More for less, in: L. Fernández-Galiano, (Ed.), Fundación Arquitectura y Sociedad (Architecture and Society Foundation)/ Arquitectura Viva (Live Architecture), Madrid, 2010, pp. 124-131. (in Spanish)

[20] M.H. Contal, J. Revedin, Sustainable Design: Towards a New Ethic in Architecture and Town Planning, Birkhäuser, Berlin, 2009.

[21] A. Aravena, Elemental: Incremental Housing and Participatory Design Manual, Hatje-Cantz, 2012. (in Spanish) 